\title{
Prognostic value of a comprehensive geriatric assessment for predicting one-year mortality in presumably frail patients with symptomatic aortic stenosis
}

\author{
Audrey Camarzana ${ }^{1}$, Cédric Annweiler², Frédéric Pinaud ${ }^{3}$, Wissam Abi-Khalili4, Frédéric Rouleau ${ }^{4}$, \\ Guillaume Duval'2 Fabrice Prunier ${ }^{4}$, Alain Furber ${ }^{4}$, Loïc Biere ${ }^{4}$
}

\author{
${ }^{1}$ Institut Mitovasc, University of Angers, Angers, France \\ ${ }^{2}$ Department of Geriatric Medicine, University Memory Center, Research Center \\ on Autonomy and Longevity, University Hospital, Angers, France; UPRES EA 4638, \\ University of Angers, Angers, France \\ ${ }^{3}$ Department of Cardiac Surgery, University Hospital of Angers, Angers, France \\ ${ }^{4}$ Institut Mitovasc, University of Angers, UMR CNRS 6015-INSERMU1083, Angers, \\ France
}

Submitted: 3 December 2018; Accepted: 16 May 2019

Online publication: 24 March 2021

Arch Med Sci 2022; 18 (6): 1446-1452

DOI: https://doi.org/10.5114/aoms/109391

Copyright @ 2021 Termedia \& Banach

\begin{abstract}
Introduction: Despite suffering a severe aortic stenosis, some patients are denied either surgical or transcatheter aortic valve implantation (TAVI) therapy because of a frail condition. We aimed to identify whether a comprehensive geriatric assessment (CGA) might be useful to predict the prognosis of presumably frail patients with severe aortic stenosis.

Material and methods: Between March 2011 and July 2016, 818 patients were consecutively and prospectively enrolled. 161 had a CGA and were considered for analysis. Considering combined CGA and heart team recommendations, 102 TAVI procedures were performed (TAVI group) and 59 patients constituted the no-TAVI group. The primary endpoint was all-cause mortality at 1 year.

Results: There was no difference between the TAVI and the no-TAVI groups considering morphometric data, cardiovascular risk factors or symptoms. The no-TAVI group had higher surgical risk (logistic EuroSCORE1 $33.4 \pm 17.8$ vs. $22.7 \pm 14.9 ; p<0.001)$ and more moderate renal insufficiency $(82 \%$ vs. $57 \% ; p=0.001)$. One-year mortality was $16 \%$ in the TAVI group and $46 \%$ in the no-TAVI group $(p<0.001)$. Multivariate analysis revealed that history of pulmonary edema, moderate renal failure, and not having a TAVI were associated with 1-year mortality. There was an interaction between the Five-Times-Sit-to-Stand-Test (FTSST) and the effect of TAVI on mortality ( $p=$ 0.049 ), as FTSST was the only predictor for 1 -year mortality in the no-TAVI group ( $\mathrm{HR}=0.18,95 \% \mathrm{Cl}: 0.04-0.76 ; p=0.019)$.

Conclusions: One-year mortality was higher in geriatric-assessed frail patients who did not undergo TAVI. FTSST, which assesses patients' mobility, was the only prognostic marker for 1-year mortality, on top of the usual medical parameters.
\end{abstract}

Key words: aortic stenosis, transcatheter aortic valve implantation, comprehensive geriatric assessment, frailty.

\author{
Corresponding author: \\ Loïc Biere MD, PhD \\ Institut Mitovasc \\ University of Angers \\ UMR CNRS \\ 6015-INSERMU1083 \\ Angers 49000, France \\ E-mail: loic.biere@gmail.com
}




\section{Introduction}

In developed western countries, aortic stenosis is the most common valvular heart disease in individuals over 65 years of age [1]. Surgical aortic valve replacement (SAVR) is the first-line therapy for symptomatic patients, improving prognosis and quality of life [2, 3].

Transcatheter aortic valve implantation (TAVI) may be performed among patients according to either a high surgical risk, a technical contraindication to surgery or a general poor condition named frailty $[4,5]$.

Frailty is a clinical syndrome combining decrease in physiological reserve and stress tolerance $[6,7]$ that can be assessed implicitly, while a comprehensive geriatric assessment (CGA) helps to globally assess medical and social issues of older adults based on a set of clinical scores, questionnaires and biological tests [8].

Heart team and geriatric evaluation units will assess every patient denied surgical therapy because of frailty to determine whether TAVI remains appropriate $[9,10]$.

The aim of the study was to identify whether CGA might be useful to improve the precision of the 1-year prognosis of presumably frail patients, whatever the management of aortic stenosis.

\section{Material and methods}

\section{Study population}

A total of eight hundred eighteen patients considered for TAVI were prospectively and consecutively enrolled between March 2011 and July 2016.

Inclusion criteria were a symptomatic severe aortic stenosis and being denied a SAVR by a heart team because of either a technical barrier (for instance porcelain aorta, chest deformation, or history of chest radiotherapy), a high preoperative risk as assessed by the EuroSCORE (a risk model for the prediction of mortality after heart surgery), or because of a heart team-assessed general poor condition to undergo thoracic surgery named frailty.

One hundred sixty-one patients presenting a general frail condition raised concerns about the direct individual benefits of undergoing TAVI; they necessitated a CGA before the final decision from the heart team and constituted the study population. The heart team included an interventional cardiologist, a non-interventional cardiologist, a heart surgeon and an anesthesiologist. The team took all CGA data into account to determine the most appropriate care.

The local ethical committee approved the research protocol (\#2017/45) and the study was conducted in accordance with the Declaration of Helsinki and local regulatory requirements.

\section{Data collection}

All data related to demographic, morphometric, and echocardiographic parameters, and medical history were prospectively collected. Pulmonary hypertension was defined as a systolic pulmonary artery pressure of more than $35 \mathrm{~mm} \mathrm{Hg}$, moderate renal insufficiency by a creatinine clearance of less than $60 \mathrm{ml} / \mathrm{min}$, respiratory insufficiency by the daily use of bronchodilator or inhaled corticosteroid, and history of pulmonary edema by at least two acute episodes during the last 12 months [11].

The CGA was performed by the geriatric evaluation unit during hospitalization to appreciate medical and social issues related to older adults. The main items were: an evaluation of polypharmacy based on the number of therapeutic classes used per day and the use of psychoactive drugs, memory by the learning and recall categories of the Mini-Mental State Examination (Short MMSE) [12] and the clock-drawing test (CDT) score [13], pain assessed by the verbal rating scale [14], nutrition by the short form of the Mini Nutritional Assessment (MNA) [15] and by the body mass index (BMI), independency by iso-resource group (GIR) [16] and Instrumental Activities of Daily Living (IADL) [17]), and mobility by the Five-Times-Sit-to-Stand Test (FTSST), which was considered as positive if accomplished without assistance and/or without use of upper extremity support [18].

\section{Follow-up and outcomes}

Follow-up was completed for all patients for at least 1 year with a median of 456 [153; 815] days. It involved immediate feedback provided by consultants and phone interview with a general practitioner. The primary endpoint was all-cause mortality at 1 year.

\section{Statistical analysis}

All statistical tests were performed using SPSS 20.0 software (IBM, Chicago, Illinois). Quantitative variables were expressed as mean \pm standard deviations, unless stated otherwise, and qualitative variables as numbers and percentages. Comparisons of quantitative variables were conducted by means of unpaired Student's $t$-test. Comparisons of qualitative variables were performed using the $\chi^{2}$ or Fisher's test, as appropriate.

Cox regression models were applied to explain 1-year all-cause mortality. Multivariate analysis included common medical data, aortic stenosis parameters, and CGA results. Only significant univariate correlates $(p<0.05)$ were included into the multivariate Cox models. Specific interactions were tested between TAVI and NYHA score, FTSST, 
Audrey Camarzana, Cédric Annweiler, Frédéric Pinaud, Wissam Abi-Khalil, Frédéric Rouleau, Guillaume Duval, Fabrice Prunier, Alain Furber, Loïc Biere

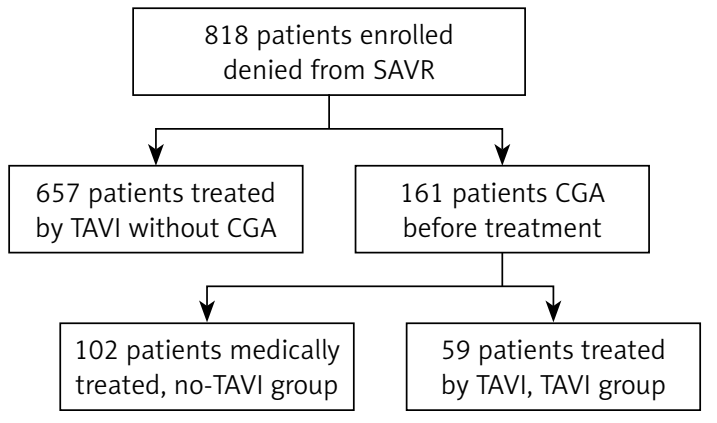

Figure 1. Flow chart

moderate renal failure and respiratory failure. Then, multivariate Cox regression models were performed separately on the TAVI and the no-TAVI groups.

Proportional-hazard assumptions were tested by analysis of the Schoenfeld residuals. Statistical significance was set at $p<0.05$.

\section{Results}

\section{Baseline characteristics}

\section{Study population}

CGA patients were older (85.9 \pm 4.6 vs. 82.8 \pm 7.1 years old, $p<0.001$ ), with higher logistic EurOSCORE $(29.5 \pm 17.5$ vs. $19.5 \pm 12.6, p<0.001)$, and lower LV ejection fraction ( $53.5 \pm 13.7$ vs. 58.7 $\pm 12.2 \%, p<0.001$ ) compared to patients who did not require CGA prior to TAVI. CGA patients presented more history of atrial fibrillation (51\% vs. $32 \%, p<0.001$ ), but similar rates of history of diabetes, peripheral artery disease, stroke, renal failure, coronary artery disease, and symptoms related to aortic stenosis.

Out of 161 CGA patients, 102 patients did not undergo a TAVI (no-TAVI group) and 59 patients underwent a TAVI (TAVI group) (Figure 1). In the TAVI group, 14 patients had a CoreValve (Medtron-

Table I. Patient characteristics at baseline, cardiovascular data

\begin{tabular}{|c|c|c|c|c|}
\hline Parameter & Total & TAVI & No-TAVI & $P$-value \\
\hline \multicolumn{5}{|l|}{ Morphometric characteristics: } \\
\hline Age [years] & $85.9 \pm 4.6$ & $85.5 \pm 5.1$ & $86.1 \pm 4.3$ & 0.4 \\
\hline Weight [kg] & $67.4 \pm 14.4$ & $69.5 \pm 14.7$ & $66.2 \pm 14.3$ & 0.17 \\
\hline Height $[\mathrm{cm}]$ & $160.8 \pm 8.4$ & $161.6 \pm 7.6$ & $160.3 \pm 8.8$ & 0.34 \\
\hline Body mass index $\left[\mathrm{kg} / \mathrm{cm}^{2}\right]$ & $26 \pm 5$ & $26.5 \pm 5$ & $25.7 \pm 5.1$ & 0.36 \\
\hline \multicolumn{5}{|l|}{ Surgical risk scores: } \\
\hline Logistic EuroSCORE 1, \% & $29.5 \pm 17.5$ & $22.7 \pm 14.9$ & $33.4 \pm 17.8$ & $<0.001$ \\
\hline STS, \% & $8.8 \pm 6$ & $6.7 \pm 4.7$ & $9.8 \pm 6.3$ & 0.003 \\
\hline \multicolumn{5}{|l|}{ Medical history, $n(\%)$ : } \\
\hline Ischemic cardiomyopathy & $67(42)$ & $22(38)$ & $45(44)$ & 0.49 \\
\hline Pacemaker & $34(21)$ & $16(28)$ & $18(17)$ & 0.12 \\
\hline Atrial fibrillation & $82(51)$ & $30(52)$ & $52(50)$ & 0.84 \\
\hline Anticoagulation therapy & $76(47)$ & $29(50)$ & $47(46)$ & 0.56 \\
\hline Balloon aortic valvuloplasty after CGA & $13(8)$ & $0(0)$ & $13(12)$ & - \\
\hline Respiratory insufficiency & $25(15)$ & $6(10)$ & $19(18)$ & 0.17 \\
\hline Stroke & $31(19)$ & $12(21)$ & $19(18)$ & 0.71 \\
\hline Moderate renal insufficiency & $117(73)$ & $33(57)$ & $84(82)$ & $<0.001$ \\
\hline \multicolumn{5}{|l|}{ Cardiovascular risks factors, $n(\%)$ : } \\
\hline Hypertension & $134(84)$ & $45(78)$ & $89(87)$ & 0.17 \\
\hline Hypercholesterolemia & $72(45)$ & $26(45)$ & $46(45)$ & 0.95 \\
\hline Smoking & $12(7)$ & $4(7)$ & $8(7)$ & 0.85 \\
\hline Diabetes & $42(26)$ & $18(31)$ & $24(23)$ & 0.27 \\
\hline \multicolumn{5}{|l|}{ Aortic stenosis parameters: } \\
\hline NYHA > $2, n(\%)$ & $99(62)$ & $41(71)$ & $58(56)$ & 0.06 \\
\hline History of pulmonary edema, $n$ (\%) & $57(35)$ & $20(35)$ & $37(36)$ & 0.88 \\
\hline Left ventricular ejection fraction, $\%$ & $53.5 \pm 13.7$ & $54 \pm 13.3$ & $53.2 \pm 13.9$ & 0.73 \\
\hline Mean pressure gradient [mm Hg] & $48.6 \pm 15.2$ & $49.2 \pm 13.9$ & $48.3 \pm 15.9$ & 0.72 \\
\hline Pulmonary hypertension, $n(\%)$ & $83(53)$ & $33(61)$ & $50(50)$ & 0.013 \\
\hline
\end{tabular}

CGA - comprehensive geriatric assessment, NYHA - New York Heart Association, STS - Society of Thoracic Surgeons, TAVI - transcatheter aortic valve implantation. 
ic, Santa Ana, CA, USA) prosthesis and 45 had an Edwards Sapien, Sapien 3 or Sapien XT prosthesis (Edwards Lifesciences, Irvine, CA, USA). Forty-four (74\%) patients had a transfemoral, 6 (10\%) a transapical and 9 (16\%) another approach. The TAVI was a success in 57 cases (96.6\%) with no relevant procedural complications.

Mean age was $85.9 \pm 4.6$ years ( $85.5 \pm 5.1$ vs. $86.1 \pm 4.3 ; p=0.40)$ and mean BMI was $26 \pm 5 \mathrm{~kg} /$ $\mathrm{cm}^{2}(26.5 \pm 5$ vs. $25.7 \pm 5.1 ; p=0.36)$.

The no-TAVI group had a higher surgical risk score (logistic EuroSCORE 1: $33.4 \pm 17.8$ vs. 22.7 $\pm 14.9 ; p<0.001)$ and higher rates of moderate renal insufficiency ( $82 \%$ vs. 57\%; $p=0.001)$.

No-TAVI and TAVI patients presented similar rates of New York Heart Association (NYHA) functional class III or IV (71\% in TAVI group vs. $56 \%$ in no-TAVI group; $p=0.06)$, history of pulmonary edema ( $35 \%$ vs. $36 \% ; p=0.88$ ), and similar left ventricular ejection fraction and transvalvular mean pressure gradient. However, there was more pulmonary hypertension in the TAVI group (61\% vs. $50 \% ; p=0.013$ ) (Table I).

\section{Geriatric characteristics}

There was no difference regarding history of falls, number of therapeutic classes used per day, use of psychoactive drugs, social isolation and needs for home care worker support.

The no-TAVI group presented more memory impairment with a lower short MMSE and CDT score (respectively $36 \%$ of MMSE3 > 5 vs. $57 \%$; $p=$ 0.013 and $1.4 \pm 2.1$ points vs. $2.7 \pm 2.4$; $p=0.025$ ).
Moreover, the no-TAVI group was more dependent with a significantly lower GIR score than the TAVI group (3.6 \pm 0.9 vs. $4.2 \pm 0.9 ; p<0.001$ ) (Table II). FTSST was achieved in $18 \%$ of the cohort (respectively $15 \%$ vs. $25 \%$ for no-TAVI and TAVI group, $p=0.20)$.

\section{One-year mortality}

One-year mortality was $16 \%(n=16)$ in the TAVI group and $46 \%(n=27)$ in the no-TAVI group $(p<0.001)$ (Figure 2).

Independent 1-year mortality correlates were: not having a TAVI performed $(\mathrm{HR}=76.9295 \% \mathrm{Cl}$ : 3.47-1707; $p=0.006)$, moderate renal insufficiency $(\mathrm{HR}=3.67,95 \% \mathrm{Cl}: 1.29-10.44 ; p=0.015)$ and a history of pulmonary edema $(\mathrm{HR}=2.15,95 \% \mathrm{Cl}$ : 1.15-3.99; $p=0.016$ ). We found an interaction for the effect of TAVI on 1-year mortality according to FTSST $(p=0.049)$ (Table III).

In the no-TAVI group, the multivariate Cox regression model performed revealed a success in FTSST to be the best predictor for 1-year mortality $(\mathrm{HR}=0.18,95 \% \mathrm{Cl}: 0.04-0.76 ; p=0.019)$. There was also a trend towards history of pulmonary edema $(\mathrm{HR}=1.81,95 \% \mathrm{Cl}: 0.97-3.37 ; p=0.06)$ and respiratory insufficiency $(\mathrm{HR}=0.36,95 \% \mathrm{Cl}$ : 0.12-1.03; $p=0.06$ ) (Table IV, Figure 3).

In the TAVI group, multivariate Cox analysis did not reveal any CGA parameter to be related to 1-year prognosis. Respiratory insufficiency $(\mathrm{HR}=40.9,95 \% \mathrm{Cl}: 6.52-257 ; p<0.001)$ and moderate renal insufficiency $(H R=11.95,95 \%$ $\mathrm{Cl}: 1.57-90.90 ; p=0.017$ ) were the predictors of 1-year mortality.

Table II. Patient characteristics at baseline, geriatrics data

\begin{tabular}{|lcccc|}
\hline Parameter & Total & TAVI & No-TAVI & $P$-value \\
\hline General characteristics: & & & & \\
\hline History of falls, $n(\%)$ & $65(43)$ & $21(38)$ & $44(45)$ & 0.41 \\
\hline Number of therapeutic classes & $7.5 \pm 2.8$ & $7.3 \pm 2.7$ & $7.7 \pm 2.8$ & 0.45 \\
\hline Psychotropic drug therapy, $n(\%)$ & $79(51)$ & $23(42)$ & $56(56)$ & 0.11 \\
\hline Exhaustion, $n$ (\%) & $58(45)$ & $19(42)$ & $39(46)$ & 0.61 \\
\hline Isolation, $n$ (\%) & $56(39)$ & $22(41)$ & $34(37)$ & 0.66 \\
\hline Homecare workers, $n$ (\%) & $120(75)$ & $38(67)$ & $82(80)$ & 0.08 \\
\hline Comprehensive geriatric assessment: & & & & \\
\hline Simple verbal scale (SVC) & $0.6 \pm 1$ & $0.4 \pm 0.8$ & $0.8 \pm 1$ & 0.07 \\
\hline Five-Times-Sit-To-Stand-Test (FTSST), $n$ (\%) & $24(18)$ & $11(25)$ & $13(15)$ & 0.20 \\
\hline Geriatric Depression Scale (GDS) $>4$ & $0.8 \pm 1$ & $0.6 \pm 0.8$ & $0.9 \pm 1.1$ & 0.11 \\
\hline Instrumental Activities of Daily Living Scale (IADL) & $1.5 \pm 1.2$ & $1.7 \pm 1.1$ & $1.4 \pm 1.2$ & 0.17 \\
\hline Short Mini Mental State Examination (short MMSE) $>5, n(\%)$ & $66(44)$ & $31(57)$ & $35(36)$ & 0.013 \\
\hline Mini Nutritional Assessment (MNA) & $8 \pm 2.2$ & $8.2 \pm 2.1$ & $7.9 \pm 2.3$ & 0.36 \\
\hline Iso-resource group (GIR) & $3.8 \pm 0.9$ & $4.2 \pm 0.9$ & $3.6 \pm 0.9$ & $<0.001$ \\
\hline Clock drawing test, au & $1.8 \pm 2.3$ & $2.7 \pm 2.4$ & $1.4 \pm 2.1$ & 0.025 \\
\hline
\end{tabular}

TAVI - transcatheter aortic valve implantation. 


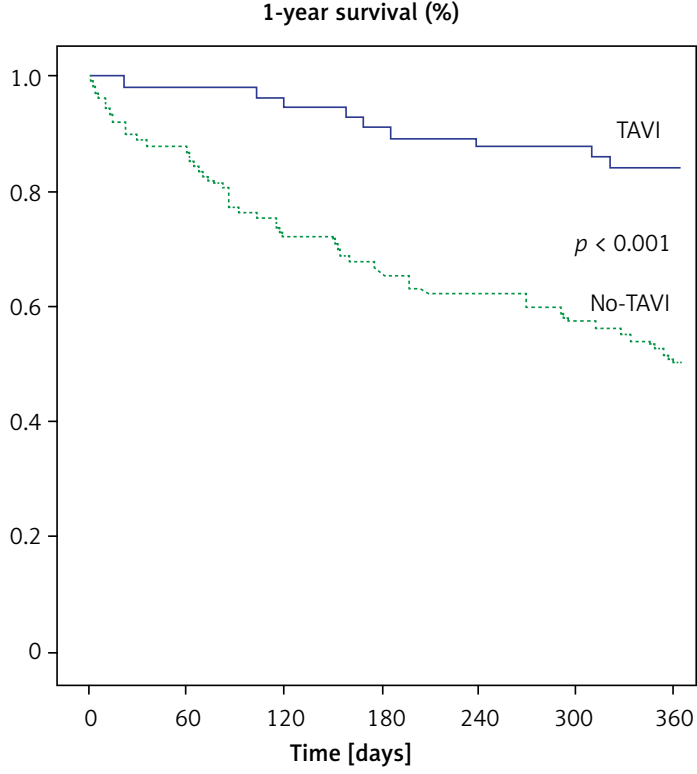

No. at risk

TAVI 59

No-TAVI

102

52

58

Figure 2. Time-to-event curves for the primary end-point

\section{Discussion}

The main results of our study are: (1) TAVI was effectively associated with reduced 1-year allcause mortality in presumably frail older patients suffering from severe aortic stenosis, and (2) FTSST was the best mortality predictor among the patients who did not undergo TAVI.

In the no-TAVI group, 1-year mortality was very high, which is consistent with previous literature $[19,20]$. Only a few recent studies have reported long-term survival of untreated severe aortic stenosis, as the last dated palliative therapy was balloon aortic valvuloplasty (BAV) in the 1990s, when 1-year mortality was around $43 \%$ without [21] and $36 \%$ with [22] BAV. On the other hand, 1-year mortality in the TAVI group was $16 \%$. Considering that our patients underwent CGA because they were presumed frail and unsuitable for TAVI, it is noticeable that this 16\% 1-year mortality remains comparable with the $21.4-24 \%$ reported by the largest national TAVI registries $[11,23]$. Beyond the TAV procedure by itself, 1-year mortality predictors were history of pulmonary edema or moderate renal failure, as previously reported by others [24, 25], but none of the CGA parameters (Table III).

In the no-TAVI group, the FTSST was the best predictor for 1-year mortality. Poor mobility was already identified as a good predictor of poor outcomes and mortality in heart disease. For in stance, the Gait Speed test - another measure of functional capacity - [26] is associated with both morbidity and mortality in older patients undergoing cardiac surgery [27]. In the TAVI population, the slowest walker and those unable to walk also presented higher mortality [28]. While loss of mobility may be inherent to the cardiac condition itself, our analysis showed the mobility assessment alone and not the usual cardiac markers to relate to mortality in the no-TAVI group. This result suggests that frail patients suffer more from a poor general mobility condition rather than a cardiac condition. We should acknowledge that every single patient from our cohort presented surgical aortic stenosis with severe symptoms (Table I), potentially explaining the fact that usual cardiac markers were not discriminant - and FTSST might relate to a worse prognosis in the general subset

Table III. One-year all-cause mortality, multivariate analysis

\begin{tabular}{|lccc|}
\hline Parameter & HR & 95\% Cl & $P$-value \\
\hline No TAVI & 76.92 & $3.47-1707$ & 0.006 \\
\hline History of pulmonary edema & 2.15 & $1.15-3.99$ & 0.016 \\
\hline Moderate renal insufficiency & 3.67 & $1.29-10.44$ & 0.015 \\
\hline FTSST success & 25.72 & $0.53-1248$ & 0.10 \\
\hline Mini nutritional assessment & 0.94 & $0.81-1.09$ & 0.42 \\
\hline Interaction between FTSST and no-TAVI & 0.01 & $0.01-0.1$ & 0.049 \\
\hline
\end{tabular}

CI - confidence interval, FTSST - Five-Time-Sit-to-Stand test, HR - hazard ratio, TAVI - transcatheter aortic valve implantation.

Table IV. One-year mortality in no-TAVI group, multivariate analysis

\begin{tabular}{|lccc|}
\hline Variable & HR & 95\% Cl & $\boldsymbol{P}$-value \\
\hline History of pulmonary edema & 1.81 & $0.97-3.37$ & 0.06 \\
\hline Moderate renal insufficiency & 2.24 & $0.77-6.54$ & 0.14 \\
\hline FTSST success & 0.18 & $0.04-0.76$ & 0.019 \\
\hline Respiratory insufficiency & 0.36 & $0.12-1.03$ & 0.06 \\
\hline
\end{tabular}

$\mathrm{Cl}$ - confidence interval, FTSST - Five-Time-Sit-to-Stand test, HR - hazard ratio, TAVI - transcatheter aortic valve implantation. 
1-year survival (\%)

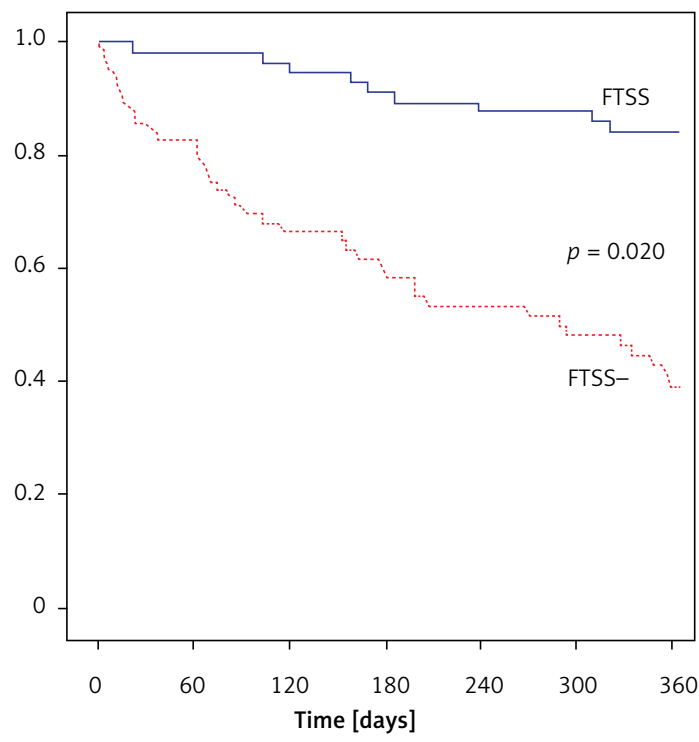

No. at risk

FTSS 12

FTSS- 70

11

35

10

Figure 3. Time-to-event curves for the primary endpoint according to the FTSST results among the no-TAVI patients

FTSST - Five-Time-Sit-to-Stand Test, FTSST - Success without assistance or with upper extremity support.

of older patients. The loss of mobility is also often related to weight loss and/or cachexia in older adults, yet mean BMI and MNA values were normal $\left(25.7 \pm 5.1 \mathrm{~kg} / \mathrm{m}^{2}\right.$ and $7.9 \pm 2.3$, respectively), and did not relate to prognosis.

Our patients are representative of patients from the beginnings of the TAVI procedure, and therefore very high-risk patients. In the new ESC recommendations [29], TAVI takes a greater part of the invasive treatment for symptomatic aortic stenosis. Indeed, TAVI will now be recommended from the age of 75, for patients with lowest surgical risk represented by a STS score $\geq 4 \%$ and a logistic EuroSCORE $\geq 10 \%$ (compared to $10 \%$ and $20 \%$ in 2012, respectively) [29]. Consequently, as TAVI will be considered in a larger number of lower risk patients, common medical comorbidities will become less prevalent and might lack accuracy in assessing long-term benefits, providing room for objective geriatric criteria.

The clinical interest of our results stems from showing evidence that TAVI improved overall survival in presumably frail patients, provided that the individual decision was approved by the CGA and heart team. Moreover, even though the present method was not meant to better identify patients who will benefit from TAVI, we highlight the possibility that investigating patients' mobility might be a cornerstone in assessing further prognosis. Whether or not physical training should be encouraged in patients with loss of mobility remains to be investigated among patients with severe aortic stenosis.

Several limitations should be considered, the first being inherent bias due to it being a retrospective and observational non-randomized study, with a limited sample size. Secondly, our study assessed a very high-risk population, with severe symptomatic aortic stenosis, which was representative of the beginning of the TAVI procedure. Third, while there is evidence that frail older patients with TAVI exhibit higher mortality [30, 31], the proportion of TAVI patients was too low to allow us to study the impact of CGA parameters on prognosis. Finally, other prognostic markers might be investigated. The Charlson comorbidity index is a validated measure of 1-year mortality risk and disease burden [32]. A low serum vitamin D level in older adults has been demonstrated to be associated with cardiovascular risk [32], dementia [33] and all-cause mortality [34].

In conclusion, aortic valve replacement by a TAVI was associated with reduced 1-year mortality among presumed frail older patients with severe aortic stenosis. FTSST was an independent predictor of 1-year mortality in patients with severe aortic stenosis who did not undergo valve replacement.

\section{Conflict of interest}

The authors declare no conflict of interest.

\section{References}

1. lung B, Baron G, Butchart EG, et al. A prospective survey of patients with valvular heart disease in Europe: the Euro Heart Survey on Valvular Heart Disease. Eur Heart J 2003; 24: 1231-43.

2. Schwarz F, Baumann P, Manthey J, et al. The effect of aortic valve replacement on survival. Circulation 1982; 66: 1105-10.

3. Lindman BR, Bonow RO, Otto CM. Current management of calcific aortic stenosis. Circ Res 2013; 113: 223-37.

4. lung B. Decision-making in elderly patients with severe aortic stenosis: why are so many denied surgery? Eur Heart J 2005; 26: 2714-20.

5. Carabello BA. Transcatheter aortic-valve implantation for aortic stenosis in patients who cannot undergo surgery. Curr Cardiol Rep 2011; 13: 173-4.

6. Bergman H, Ferrucci L, Guralnik J, et al. Frailty: an emerging research and clinical paradigm: issues and controversies. J Gerontol A Biol Sci Med Sci 2007; 62: 731-7.

7. Pel-Littel RE, Schuurmans MJ, Emmelot-Vonk MH, Verhaar HJJ. Frailty: defining and measuring of a concept. J Nutr Health Aging 2009; 13: 390-4.

8. Wieland D, Hirth V. Comprehensive geriatric assessment. Cancer Control J Moffitt Cancer Cent 2003; 10: 454-62.

9. Coylewright M, Mack MJ, Holmes DR, O'Gara PT. A call for an evidence-based approach to the Heart Team for patients with severe aortic stenosis. J Am Coll Cardiol 2015; 65: 1472-80. 
10. Sintek M, Zajarias A. Patient evaluation and selection for transcatheter aortic valve replacement: the heart team approach. Prog Cardiovasc Dis 2014; 56: 572-82.

11. Gilard M, Eltchaninoff $H$, lung B, et al.; FRANCE 2 Investigators. Registry of transcatheter aortic-valve implantation in high-risk patients. N Engl J Med 2012; 366: 1705-15.

12. Haubois G, de Decker L, Annweiler C, et al. Derivation and validation of a Short Form of the Mini-Mental State Examination for the screening of dementia in older adults with a memory complaint. Eur J Neurol 2013; 20: 588-90.

13. Gagliese L, Weizblit N, Ellis W, Chan VWS. The measurement of postoperative pain: a comparison of intensity scales in younger and older surgical patients. Pain 2005 ; 117: 412-20.

14. Kaiser MJ, Bauer JM, Ramsch C, et al. Validation of the Mini Nutritional Assessment short-form (MNA-SF) a practical tool for identification of nutritional status. J Nutr Health Aging 2009; 13: 782-8.

15. Vetel JM, Leroux R, Ducoudray JM. AGGIR. Practical use. Geriatric Autonomy Group Resources Needs. Soins Gerontol 1998; 13: 23-7.

16. Barberger-Gateau P, Commenges D, Gagnon M, Letenneur L, Sauvel C, Dartigues JF. Instrumental activities of daily living as a screening tool for cognitive impairment and dementia in elderly community dwellers. J Am Geriatr Soc 1992; 40: 1129-34.

17. Buatois S, Miljkovic D, Manckoundia P, et al. Five times sit to stand test is a predictor of recurrent falls in healthy community-living subjects aged 65 and older. J Am Geriatr Soc 2008; 56: 1575-7.

18. Braunwald's Heart Disease. $10^{\text {th }}$ ed. Mann DL, Braunwald E (eds.) Elsevier, Saunders, Philadelphia, Pa 2015.

19. Chizner MA, Pearle DL, deLeon AC. The natural history of aortic stenosis in adults. Am Heart J 1980; 99: 419-24.

20. O'Keefe JH, Vlietstra RE, Bailey KR, Holmes DR. Natural history of candidates for balloon aortic valvuloplasty. Mayo Clin Proc 1987; 62: 986-91.

21. Lieberman EB, Bashore TM, Hermiller JB, et al. Balloon aortic valvuloplasty in adults: failure of procedure to improve long-term survival. J Am Coll Cardiol 1995; 26: 1522-8.

22. Moat NE, Ludman P, de Belder MA, et al. Long-term outcomes after transcatheter aortic valve implantation in high-risk patients with severe aortic stenosis: the U.K. TAVI (United Kingdom Transcatheter Aortic Valve Implantation) Registry. J Am Coll Cardiol 2011; 58: 2130-8.

23. Oguri A, Yamamoto $M$, Mouillet $G$, et al. Impact of chronic kidney disease on the outcomes of transcatheter aortic valve implantation: results from the FRANCE 2 registry. Eurolntervention J Eur Collab Work Group Interv Cardiol Eur Soc Cardiol 2015; 10: e1-9.

24. Furuta A, Lellouche N, Mouillet G, et al. Impact of previous acute pulmonary oedema after transcatheter aortic valve implantation: insight from French Aortic National CoreValve and Edwards 2 [FRANCE 2] registry. Int J Cardiol 2015; 183: 98-104.

25. Montero-Odasso $M$, Schapira $M$, Soriano $E R$, et al. Gait velocity as a single predictor of adverse events in healthy seniors aged 75 years and older. J Gerontol A Biol Sci Med Sci 2005; 60: 1304-9.

26. Afilalo J, Eisenberg MJ, Morin JF, et al. Gait speed as an incremental predictor of mortality and major morbidity in elderly patients undergoing cardiac surgery. J Am Coll Cardiol 2010; 56: 1668-76.

27. Kano S, Yamamoto M, Shimura T, et al. Gait speed can predict advanced clinical outcomes in patients who un- dergo transcatheter aortic valve replacement: insights from a Japanese Multicenter Registry. Circ Cardiovasc Interv 2017; 10: e005088.

28. Baumgartner H, Falk V, Bax J, et al. 2017 ESC/EACTS Guidelines for the management of valvular heart disease. Eur Heart J 2017; 38: 2739-91.

29. Anand A, Harley C, Visvanathan A, et al. The relationship between preoperative frailty and outcomes following transcatheter aortic valve implantation: a systematic review and meta-analysis. Eur Heart J Qual Care Clin Outcomes 2017; 3: 123-32.

30. Zahn R, Werner N, Gerckens U, et al. Five-year follow-up after transcatheter aortic valve implantation for symptomatic aortic stenosis. Heart Br Card Soc 2017; 103: 1970-6.

31. Roffman CE, Buchanan J, Allison GT. Charlson Comorbidities Index. J Physiother 2016; 62: 171.

32. Brondum-Jacobsen P, Benn M, Jensen GB, Nordestgaard BG. 25-Hydroxyvitamin D levels and risk of ischemic heart disease, myocardial infarction, and early death: population-based study and meta-analyses of 18 and 17 studies. Arterioscler Thromb Vasc Biol 2012; 32 : 2794-802.

33. Littlejohns TJ, Henley WE, Lang IA, et al. Vitamin D and the risk of dementia and Alzheimer disease. Neurology 2014; 83: 920-8.

34. Pludowski P, Holick MF, Pilz S, et al. Vitamin D effects on musculoskeletal health, immunity, autoimmunity, cardiovascular disease, cancer, fertility, pregnancy, dementia and mortality - a review of recent evidence. Autoimmun Rev 2013; 12: 976-89. 